\title{
A Brief Review on Electro-generated Hydroxyl Radical for Organic Wastewater Mineralization
}

\author{
Ervin Nurhayati \\ PhD Student at Institute of Environmental Engineering, \\ National Chiao Tung University, 1001 University Road, Hsinchu 300, Taiwan. \\ e-mail:ervinn.ev99g@nctu.edu.tw
}

\begin{abstract}
Hydroxyl radical is a highly reactive oxidizing agent that can be electrochemically generated on the surface of Boron doped diamond (BDD) anode. Once generated, this radical will non-selectively mineralize organic pollutants to carbon dioxide, water and organic anions as the oxidation products. Its application in Advanced Oxidation Process (AOP) to degrade nonbiodegradable even the recalcitrant pollutants in wastewater has been increasingly studied and even applied.
\end{abstract}

Keywords: Advanced Oxidation Process, Boron Doped Diamond, Hydroxyl radical, Organic pollutants

\section{Introduction}

Biological processes, so far is the most economically preferred technique for organic wastewater treatment. However, many industrial wastewaters contain complex organics that possibly biologically inert or even toxic for microorganism involve in the respective processes. Physicochemical process such as filtration, coagulation, adsorption, and flocculation, and chemical oxidation by means of adding oxidation agents such as chlorine, ozone, hydrogen peroxide or even wet air oxidation are among other popular industrial organic wastewater treatment but not always sufficient to completely removed all pollutants (Panizza and Cerisola, 2009; Saez et al., 2007; and Comninellis et al., 2008).

Conventional process used to treat wastewater from textile industry includes chemical precipitation with alum or ferrous sulphate which suffers from drawbacks such as generation of a large volume of sludge leading to the disposal problem, and also the contamination of chemical substances in the treated wastewater. Moreover these processes are inefficient in completely oxidizing dyestuffs and organic compounds of complex structure (Shashank Singh Kalra, 2011).

Another highly favorable alternative is Advanced Oxidation Process (AOPs). AOPs generally defined as aqueous phase oxidation methods based on the intermediacy of highly reactive species such as (primarily but not exclusively) hydroxyl radicals $(\bullet \mathrm{OH})$ in the mechanisms leading to the destruction of the target pollutant (Comninellis et al., 2008). This physicochemical method, based on the production and use of hydroxyl radical have been successfully tested for elimination of many kind of compounds in water (Comninellis et al., 2008; Palma-Goyes et al., 2010). 
The aim of AOP is the generation of free hydroxyl radicals $(\bullet \mathrm{OH})$, a powerful, highly reactive, nonselective oxidizing agent which acts very rapidly with most organic compounds and destroy even the recalcitrant pollutants. Once generated, the hydroxyl radicals aggressively attack virtually all organic compounds (Munter, 2001).

There are several currently known methods for hydroxyl radicals generation such as $\mathrm{H}_{2} \mathrm{O}_{2} / \mathrm{UV}$, $\mathrm{UV} / \mathrm{O}_{3}, \mathrm{H}_{2} \mathrm{O}_{2} / \mathrm{O}_{3}, \mathrm{TiO}_{2}$ photocatalysis, Fenton's reagent, photo-Fenton ultrasound (US) and wet air oxidation (WAO), while less conventional and less popular processes include ionising radiation, microwaves, pulsed plasma and the ferrate reagent (Comninellis et al., 2008; Palma-Goyes et al., 2010). Munter (2001) classified them as photochemical and non-photochemical methods based on the presence or absence of light energy. Above mentioned $\bullet \mathrm{OH}$ generation methods is not the focus of this present study and will not be further discussed here.

\section{Electrochemical Mineralization and Electro-generated Hydroxyl}

Hydroxyl radical $(\bullet \mathrm{OH})$ can also be produced electrochemically by employing electrolysis process. In order to do so, water should be activated, by electrolytic discharge of water at potential above its thermodynamic stability (Martínez-Huitle and Brillas, 2009). According to this mechanism, in acidic media, water is discharged (1.23 V/SHE under standard condition) on the electrode (M) to produce hydroxyl radical $(\cdot \mathrm{OH})(1)$ on the surface of the electrode which actually is the main reaction intermediates for $\mathrm{O}_{2}$ evolution (2):

$$
\begin{aligned}
& \mathrm{H}_{2} \mathrm{O}+\mathrm{M} \rightarrow \mathrm{M}(\bullet \mathrm{OH})+\mathrm{H}^{+}+\mathrm{e}^{-} \\
& \mathrm{M}(\bullet \mathrm{OH}) \rightarrow \mathrm{M}+1 / 2 \mathrm{O}_{2}+\mathrm{H}^{+}+\mathrm{e}^{-}
\end{aligned}
$$

The electrochemical oxidation of organic compound $(\mathrm{R})$ by electrogenerated hydroxyl radical then takes place close to the surface of the anode according to this (simplified) equation:

$$
\mathrm{R}_{(\mathrm{aq})}+\mathrm{M}(\cdot \mathrm{OH})_{\mathrm{n} / 2} \rightarrow \mathrm{M}+\text { Oxidation product }+\mathrm{n} / 2 \mathrm{H}^{+}+\mathrm{e}^{-}
$$

where $\mathrm{n}$ is the number of electron involved in oxidation reaction of organic $\mathrm{R}$.

Chemical reaction with electrogenerated species from water discharge at the anode such as physically adsorbed "active oxygen" (physisorbed hydroxyl radical $\bullet \mathrm{OH}$ ) as mentioned above is categorized as indirect anodic oxidation, while direct anodic oxidation refer to the oxidation process occurred due to direct electron transfer between the pollutant and the anode which usually yield a poor decontamination (Martínez-Huitle and Brillas, 2009). 
Because of the strong reactivity of $\bullet \mathrm{OH}$, it can potentially mineralize organic pollutants into carbon dioxide, water and organic anions as the oxidation products. This particular AOP technique is clean and able to decompose a great number of compounds with selectivity. Besides to its environmental compatibility, the electrochemical process presents important advantages related to its versatility, high energy efficiency, amenability of automation and safety because it operates at mild conditions. Electrochemical oxidation is classified as electrochemical advanced oxidation process (EAOP) and consists in the oxidation of pollutants in an electrolytic cell by chemical reaction with electrogenerated species from water discharge at the anode (Migliorini et al., 2011).

\section{Importance of Anode Material}

There are several parameters that influence the efficiency of this electrochemical processes such as pollutants concentration, $\mathrm{pH}$, applied current intensity, and supporting electrolyte, but apparently the most important and major influence comes from the kind of electrode material being used (Peralta-Hern et al., 2012).

The side reaction of the anodic discharge of hydroxyl radicals to oxygen (2) will occur competitively with the reaction of organics with electrogenerated electrolytic hydroxyl radicals (3). The interaction of hydroxyl radicals with the electrode surface $M$ will affect the activity (rate of reaction (2) and (3). The general rule is, the weaker the interaction, the lower is the electrochemical activity (reaction (2) is slow) toward oxygen evolution (high $\mathrm{O}_{2}$ overvoltage anodes) and the higher is the chemical reactivity toward organics oxidation.

Comninellis (1994) categorized electrodes based on its behavior towards interaction with hydroxyl radicals it produced, namely "active" anodes, for example $\mathrm{Pt}, \mathrm{IrO}_{2}$ and $\mathrm{RuO}_{2}$ and "non-active" anodes such as and $\mathrm{PbO}_{2}, \mathrm{SnO}_{2}$ and $\mathrm{BDD}$ (Comninellis, 1994). Assuming that the initial reaction in both kind of anodes (M) corresponds to the oxidation of water molecules leading to the formation of physisorbed hydroxyl radical (1), the subsequent reaction that will occur then will be determined by the type of the anode.

When higher oxidation states are available for a metal oxide anode, above the standard potential for oxygen evolution $\left(E^{0}=1.23 \mathrm{~V}\right.$ vs. SHE) then the surface of surface of so called active anodes will interact strongly with $\bullet \mathrm{OH}$ and cause the formation of higher oxide or superoxide (MO) according to following reaction (4).

$$
\mathrm{M}(\cdot \mathrm{OH}) \rightarrow \mathrm{MO}+\mathrm{H}^{+}+\mathrm{e}^{-}
$$


Oxidation of organics will follow reaction (5) mediated by the redox couple $\mathrm{MO} / \mathrm{M}$, but there will be competition with the side reaction of oxygen evolution via chemical decomposition of the higher oxide species from reaction (6).

$$
\begin{aligned}
& \mathrm{MO}+\mathrm{R} \rightarrow \mathrm{M}+\mathrm{RO} \\
& \mathrm{MO} \rightarrow \mathrm{M}+(1 / 2) \mathrm{O}_{2}
\end{aligned}
$$

When the surface of the anode in discussion is weakly interact with $\bullet \mathrm{OH}$ then this non-active anode will allow organics to directly react with $\mathrm{M}(\bullet \mathrm{OH})$ to produce completely oxidized products such as $\mathrm{CO}_{2}$ following reaction (7).

$$
a \mathrm{M}(\cdot \mathrm{OH})+\mathrm{R} \rightarrow a \mathrm{M}+m \mathrm{CO}_{2}+n \mathrm{H}_{2} \mathrm{O}+x \mathrm{H}^{+}+y \mathrm{e}^{-}
$$

where $\mathrm{R}$ is an organic compound with $m$ carbon atoms and without any heteroatom, which needs a $=(2 \mathrm{~m}+\mathrm{n})$ oxygen atoms to be totally mineralized to $\mathrm{CO}_{2}$. Reaction (5) is much more selective than the mineralization reaction (7) with physisorbed heterogeneous hydroxyl radical that also competes with the side reactions (2) (Martínez-Huitle and Brillas, 2009; Christos Comninellis, 2010).

A non-active electrode simply acts as an inert substrate and as a sink for the removal of electrons without any involvement in the direct anodic reaction of organics and nor providing any catalytic active site for their adsorption from the aqueous medium. Hydroxyl radical produced from water discharge by reaction (1) is subsequently involved in the oxidation process of organics (MartínezHuitle and Brillas, 2009).

Boron-doped diamond-based anode (BDD) is a typical high oxidation power anode that exhibits a very weak interaction hydroxyl radical it produces (no free $\mathrm{p}$ or $\mathrm{d}$ orbitals on BDD. These considered quasi-free hydroxyl radicals, which related to the high overpotential for oxygen evolution on BDD anodes, are very reactive and can result in the mineralization of the organic compounds through following reaction (Christos Comninellis, 2010):

$$
\mathrm{R}_{(\mathrm{aq})}+\mathrm{BDD}(\cdot \mathrm{OH})_{\mathrm{n} / 2} \rightarrow \mathrm{M}+\text { Oxidation product }+\mathrm{n} / 2 \mathrm{H}^{+}+\mathrm{e}^{-}
$$

It is important to note that oxygen evolution on BDD occurs with a high overpotential with respect to thermodynamic potential for $\mathrm{O}_{2}$ formation $(\mathrm{E} \circ \mathrm{OER}=1.23 \mathrm{~V}$ vs. SHE), but is very close to the thermodynamic potential of $\mathrm{HO} \bullet$ formation $(\mathrm{E} \circ \mathrm{HO}=2.38 \mathrm{~V}$ vs. SHE) (Kapalka, Foti and Comninellis, 2009).

\section{Recent Application of BDD for Organic Wastewater Anodic Oxidation}

As mentioned above, via electrolysis process considerably large amount of electrogenerated $\bullet \mathrm{OH}$ retains weak interaction with the surface of BDD anodes resulted in a high reactivity towards organics that in turn will incinerate those organics and totally mineralize them. But not until the past 
10 years, the boron-doped diamond anode received researcher's attention and became an attractive material for numerous environmental applications (Peralta-Hern et al., 2012; Panizza and Cerisola, 2005).

Peralta-Hern, et al. (2012) presented a thorough review on electrochemical treatment processes for oxidation of synthetic dye compounds with the use of BDD anodes. Evidently BDD anodes always offer the most advantages regarding removal efficiency and decontamination of wastewaters, compared to $\mathrm{Ti} / \mathrm{Sb}_{2} \mathrm{O}_{5}-\mathrm{SnO}_{2}, \mathrm{Pt} / \mathrm{Ti}$, $\mathrm{TiRuO}_{2}$, and $\mathrm{PbO}_{2}$ with respect to its high stability, high activity towards organic oxidation and low cost. Satisfactorily color removal and COD decay (ranging from $80-100 \%$ ) of many kind of dyestuffs being studied, such as 3,4,5-trihydroxybenzoic acid, Remazol Brilliant Blue, Acid Yellow 1, O-toluidine, Basic Blue 3, Crystal Violet, Acid Black 210, Orange II, and Alizarin Red S were achieved.

However, the oxidation mechanism seems to be dependent on the nature of the dye. Investigating the degradation of Alizarin Red and Eriochrome Black T using BDD electrode under different experimental condition, Saez et. al. (2007) showed that complete COD and colour removal was obtained regardless of the current density, temperature and initial dye concentration in the electrochemical oxidation of AR and EBT under respective condition. However, it was found that the electrochemical oxidation of AR leads to almost direct generation of carbon dioxide, without accumulation in the system of large amounts of intermediates. In contrast, the EBT oxidation process starts with breakage of the azoic group and continues with oxidation of the intermediates generated.

Combining electrochemical process with other process to achieve even more enhanced result seems to be another trend. Diego et. al. (2011) combined reverse osmosis and nanofiltration membranes with the electrochemical oxidation using $\mathrm{BDD}$ as the anode to treat wastewaters containing persistent pollutants. Phenol and Acid Orange 7 dye were used as model pollutants. Overall, efficiency of the treatment obtained was significantly high. The results showed that very high COD removal values can be obtained in both the cases of phenol and AO7, above 95\%.

While conventional methods will require multistep sequence to degrade guaiacol derivatives, Kriste et al (2011) showed that anodic treatment on boron-doped diamond electrodes (BDD) provides a direct access to nonsymmetrical biphenols to instantly degrade them.

The influence of several operating parameters (applied current density, initial organics concentration, temperature, flow rate and initial $\mathrm{pH}$ value) on anodic oxidation process using BDD to degrade sinapinic acid (4-hydroxy-3,5-dimethoxy-cinnamic acid), one of the most representative polyphenolic type compounds present in olive oil mill wastewater was investigated by Elaoud et al 
(2011). Color degradation and COD removal were observed to study the reaction kinetics of sinapinic acid mineralization. Again, BDD showed its superiority in producing electrogenerated hydroxyl radicals on its surface to almost completely removing COD. Moreover, the COD removal follows a pseudo first-order kinetics and the apparent rate constant increased with flow rate and temperature, while applied current and $\mathrm{pH}$ shows insignificant effect. Under experimental optimal condition (flow rates $300 \mathrm{~L} \mathrm{~h}^{-1}$, temperature $50^{\circ} \mathrm{C}$, and current density $10 \mathrm{~mA} \mathrm{~cm}$ ) within $3 \mathrm{~h}$ electrolysis $97 \%$ of COD was removed and $17 \mathrm{kWh} \mathrm{m}^{-3}$ energy was consumed (Elaoud et al., 2011). Comparison of BDD and Pt electrodes in performing anodic oxidation of atenolol, known as $\beta$ blocker, has been investigated by Murugananthan et al. (2011) under the presence of $\mathrm{NaCl}, \mathrm{Na}_{2} \mathrm{SO}_{4}$ and $\mathrm{NaNO}_{3}$. The BDD anode was found to be effective in the presence of $\mathrm{Na}_{2} \mathrm{SO}_{4}$ while Pt anode exhibits better removal in the presence of $\mathrm{NaCl}$. Both $\mathrm{BDD}$ and $\mathrm{Pt}$ anode performance on the mineralization of atenolol were significantly depend on the initial concentration of $\mathrm{NaCl}$ and applied current density. Initially it was observed that the rate of mineralization on Pt were higher but in fact the overall rate of mineralization is more or less similar after $15 \mathrm{~h}$ of electrooxidation. The presence of residual chlorinated organic compounds which are very refractive contributed to the slow degradation process at the later stages of electrooxidation. Again, The complete mineralization was achieved using $\mathrm{BDD}$ as anode, this time in the presence of $\mathrm{Na}_{2} \mathrm{SO}_{4}$ (Murugananthan et al., 2011).

An attempt was done by Petrucci and Montanaro (2011) to examine BDD electrode performance in a system that resembles the complexness of real wastewater containing the Reactive Blue 19 dye, taken after the rinse and softening bath from a typical reactive dyes process. This effluent is a complex mixture of dyes, electrolytes at high concentration, mainly chlorides or sulphates and carbonates together with dyeing auxiliaries. The efficiency of the process was evaluated by observing the colour, chemical oxygen demand (COD) and total organic carbon (TOC) removal. This study results in the proof that carbonate presence is negatively affected the color removal while complete mineralization was found to mainly depend only on temperature. The study of current density effect conclude that discoloration mainly occurs via oxidation mediated by electrogenerated active chlorine while COD and TOC removal is primarily due to oxidation by means of hydroxyl radicals produced at BDD surface.

A study has successfully scaled-up boron-doped diamond (BDD) anode system $\left(24 \mathrm{~cm}^{2}\right)$ in continuous mode electrochemical oxidation of phenol simulated wastewater to over 100 times larger $\left(2904 \mathrm{~cm}^{2}\right)$ with expectedly relatively the same level of COD degradation efficiency and specific energy consumption. At the optimized conditions, the larger BDD anode system could 
easily reduce the COD of phenol simulated wastewater from $633 \mathrm{mg} \mathrm{L}^{-1}$ to $145 \mathrm{mg} \mathrm{L}^{-1}$ during 80 minutes operation with specific energy consumption only $31 \mathrm{kWh} \mathrm{kg} \mathrm{COD}^{-1}$ (Zhu et al., 2010).

Numerous studies have also been conducted to investigate BDD performance to anodically oxidize other kind of complex organics such as pesticide, drugs and surfactants (Panizza et al., 2005; Brillas, et al., 2004; Cañizares et al., 2009).

\section{Summary}

AOP technique is clean and able to decompose a great number of organic compounds. It possess advantageous in term of environmental compatibility, versatility, high energy efficiency, amenability of automation and safety because it operates at mild conditions. Electrogenerated hydroxyl radical produced on the inert surface of BDD is a very strong reactive oxidizing agent that capable of mineralizing organics especially the nonbiodegradable ones. Its non-selective nature on oxidizing pollutants opens a wide possibility in environmental application.

\section{References}

Panizza, M., and Cerisola, G. (2009). Direct and mediated anodic oxidation of organic pollutants. Chemical Reviews, 109(12): p. 6541-6569.

Saez, C., et al. (2007). Electrochemical incineration of dyes using a boron-doped diamond anode. Journal of Chemical Technology \& Biotechnology, 82(6): p. 575-581.

Comninellis, C., et al. (2008). Advanced oxidation processes for water treatment: advances and trends for R\&D. Journal of Chemical Technology \& Biotechnology, 83(6): p. 769-776.

Shashank Singh Kalra, S.M. (2011). Alok Sinha and Gurdeep Singh. Advanced Oxidation Processes for Treatment of Textile and Dye Wastewater: A Review. in 2nd International Conference on Environmental Science and Development. Singapore: IACSIT Press.

Palma-Goyes, R.E., et al. (2010). Electrochemical degradation of crystal violet with BDD electrodes: Effect of electrochemical parameters and identification of organic by-products. Chemosphere, 81(1): p. 26-32.

Munter, R. (2001). ChemInform Abstract: Advanced Oxidation Processes: Current Status and Prospects. ChemInform, 32(41): p. no-no.

Martínez-Huitle, C.A., and Brillas, E. (2009). Decontamination of wastewaters containing synthetic organic dyes by electrochemical methods: A general review. Applied Catalysis B: Environmental, 87(3-4): p. 105-145.

Migliorini, F.L., et al. (2011). Anodic oxidation of wastewater containing the Reactive Orange 16 Dye using heavily boron-doped diamond electrodes. Journal of Hazardous Materials, 192(3): p. 1683-1689. 
Peralta-Hern, et al. (2012). A Brief Review on Environmental Application of Boron Doped Diamond Electrodes as a New Way for Electrochemical Incineration of Synthetic Dyes. International Journal of Electrochemistry.

Comninellis, C. (1994). Electrocatalysis in the Electrochemical Conversion/Combustion of Organic Pollutants for Waste-Water Treatment. Electrochimica Acta, 39(11-12): p. 1857-1862.

Christos Comninellis, G.C. (2010). Electrochemistry for the environment, London: Springer

Kapalka, A., Foti, G., and Comninellis, C. (2009). The importance of electrode material in environmental electrochemistry Formation and reactivity of free hydroxyl radicals on borondoped diamond electrodes. Electrochimica Acta, 54(7): p. 2018-2023.

Panizza, M., and Cerisola, G. (2005). Application of diamond electrodes to electrochemical processes. Electrochimica Acta, 51(2): p. 191-199.

Diogo, J.C., Morão, A., and Lopes, A. (2011). Persistent aromatic pollutants removal using a combined process of electrochemical treatment and reverse osmosis/nanofiltration. Environmental Progress and Sustainable Energy, 30(3): p. 399-408.

Kirste, A., Schnakenburg, G., and Waldvogel, S.R. (2011). Anodic coupling of guaiacol derivatives on boron-doped diamond electrodes. Org Lett, 13(12): p. 3126-9.

Elaoud, S.C., et al. (2011). Electrochemical degradation of sinapinic acid on a BDD anode. Desalination, 272(1-3): p. 148-153.

Murugananthan, M., et al. (2011). Role of electrolyte on anodic mineralization of atenolol at boron doped diamond and Pt electrodes. Separation and Purification Technology, 79(1): p. 56-62.

Petrucci, E. and Montanaro, D. (2011). Anodic oxidation of a simulated effluent containing Reactive Blue 19 on a boron-doped diamond electrode. Chemical Engineering Journal, 174(2-3): p. 612-618.

Zhu, X., et al. (2010). Scale-up of BDD anode system for electrochemical oxidation of phenol simulated wastewater in continuous mode. J Hazard Mater, 184(1-3): p. 493-8.

Panizza, M., Delucchi, M., and Cerisola, G. (2005). Electrochemical degradation of anionic surfactants. Journal of Applied Electrochemistry, 35(4): p. 357-361.

Brillas, E., et al. (2004). Electrochemical destruction of chlorophenoxy herbicides by anodic oxidation and electro-Fenton using a boron-doped diamond electrode. Electrochimica Acta, 49(25): p. 4487-4496.

Cañizares, P., et al. (2009). A comparison between Conductive-Diamond Electrochemical Oxidation and other Advanced Oxidation Processes for the treatment of synthetic melanoidins. Journal of Hazardous Materials, 164(1): p. 120-125. 